\title{
Porcine cysticercosis (Taenia solium and Taenia asiatica): mapping occurrence and areas potentially at risk in East and Southeast Asia
}

Uffe Christian Braae ${ }^{\text {* }^{*}}$, Nguyen Manh Hung ${ }^{2}$, Fadjar Satrija ${ }^{3}$, Virak Khieu ${ }^{4}$, Xiao-Nong Zhou ${ }^{5}$ and Arve Lee Willingham"

\begin{abstract}
Background: Due to the relative short life span and the limited spatial movement, porcine cysticercosis is an excellent indicator of current local active transmission. The aim of this study was to map at province-level, the occurrence of T. solium and T. asiatica in pigs and areas at risk of transmission to pigs in East and Southeast Asia, based on the density of extensive pig production systems and confirmed reports of porcine cysticercosis.

Methods: This study covered East and Southeast Asia, which consist of the following countries: Brunei, Cambodia, China, East Timor, Indonesia, Japan, Laos, Malaysia, Mongolia, Myanmar, North Korea, Philippines, Singapore, South Korea, Thailand and Vietnam. Literature searches were carried out to identify current epidemiological data on the occurrence of porcine cysticercosis caused by T. solium and T. asiatica infections. Modelled densities of pigs in extensive production systems were mapped and compared to available data on porcine cysticercosis.

Results: Porcine cysticercosis was confirmed to be present during the period 2000 to 2018 in eight out of the 16 countries included in this study. Taenia solium porcine cysticercosis was confirmed from all eight countries, whereas only one country (Laos) could confirm the presence of $T$. asiatica porcine cysticercosis. Province-level occurrence was identified in five countries (Cambodia, Indonesia, Laos, Myanmar, and Vietnam) across 19 provinces. Smallholder pig keeping is believed to be widely distributed throughout the region, with greater densities predicted to occur in areas of China, Myanmar, Philippines and Vietnam.

Conclusions: The discrepancies between countries reporting taeniosis and the occurrence of porcine cysticercosis, both for T. solium and T. asiatica, suggests that both parasites are underreported. More epidemiological surveys are needed to determine the societal burden of both parasites. This study highlights a straightforward approach to determine areas at risk of porcine cysticercosis in the absence of prevalence data.
\end{abstract}

Keywords: Taenia solium, Taenia asiatica, Mapping, Tapeworm, Neglected Tropical Disease (NTD), Zoonosis, Pigs, Cysticercosis, Taeniosis, East and Southeast Asia

\footnotetext{
* Correspondence: ucbraae@gmail.com

${ }^{1}$ One Health Center for Zoonoses and Tropical Veterinary Medicine, Ross

University School of Veterinary Medicine, Basseterre, Saint Kitts and Nevis

Full list of author information is available at the end of the article
}

(c) The Author(s). 2018 Open Access This article is distributed under the terms of the Creative Commons Attribution 4.0 International License (http://creativecommons.org/licenses/by/4.0/), which permits unrestricted use, distribution, and reproduction in any medium, provided you give appropriate credit to the original author(s) and the source, provide a link to the Creative Commons license, and indicate if changes were made. The Creative Commons Public Domain Dedication waiver (http://creativecommons.org/publicdomain/zero/1.0/) applies to the data made available in this article, unless otherwise stated. 


\section{Background}

Pigs can become infected with Taenia solium or Taenia asiatica if eggs excreted from human tapeworm carriers are ingested. Although, both parasites cause human health concerns, only $T$. solium causes neurocysticercosis, which is a major public health burden globally $[1,2]$. In addition, both parasites have an economic impact on livestock sectors. Taenia solium and T. asiatica share the same transmission pathways from humans to pigs, and back to humans again. Parasite transmission can therefore be addressed with similar intervention approaches.

Taenia solium is present throughout the Americas [3], sub-Saharan Africa [4], and believed to be widely endemic in East and Southeast Asia [5]. However, information on the distribution of porcine cysticercosis within East and Southeast Asia, whether due to T. solium or $T$. asiatica, is sparse. Due to the relative short life span and the limited spatial movement, porcine cysticercosis infected pigs are excellent indicators of current local active transmission. Keeping pigs in extensive production systems whereby access to human waste is more accessible compared to intensive production systems, is considered the main risk factor for porcine cysticercosis in many regions [6]. The presence of pigs in extensive systems could therefore be used as a first indicator of areas at risk of porcine cysticercosis transmission [3]. The aim of this study was to map, at first-level administrative subdivision level, the occurrence of T. solium and T. asiatica in pigs and areas at risk of transmission to pigs in East and Southeast Asia, based on the occurrence of smallholder pig production systems and confirmed reports of porcine cysticercosis (T. solium and T. asiatica).

\section{Methods}

\section{Study area}

This study covered East and Southeast Asia, which consist of the following countries: Brunei (Negara Brunei Darussalam), Cambodia, China, East Timor, Indonesia, Japan, Laos, Malaysia, Mongolia, Myanmar, North Korea, Philippines, Singapore, South Korea, Thailand and Vietnam.

\section{Data extraction from published and grey literature}

Literature searches were carried out to identify epidemiological field surveys or routine slaughter surveys with current data (from year 2000) on the occurrence of porcine cysticercosis caused by $T$. solium and T. asiatica infections in East and Southeast Asia. Thus, porcine cysticercosis in this paper only concerns $T$. solium and $T$. asiatica unless otherwise stated. We performed a literature search using PubMed (http://www.ncbi.nlm.nih.gov/pubmed/) with a date restriction from 1st January 2000 to 30th June 2018, and the search term: "Taenia solium" OR "Taenia asiatica" OR "swine cysticercosis"
OR "porcine cysticercosis" OR "pig cysticercosis") AND ("Brunei Darussalam" OR "Cambodia" OR "China" OR "East Timor" OR "Hong Kong" OR "Indonesia" OR "Japan” OR "Laos" OR "Macau” OR "Malaysia” OR "Mongolia” OR "Myanmar" OR "Burma” OR "Korea" OR "Philippines" OR "Singapore" OR "Taiwan" OR "Thailand" OR "Vietnam"). The full search output is available in Additional file 1: Table S1. During the initial search phase, titles and abstracts were screened followed by full text review, based on the following exclusion criteria: (i) not dealing with porcine cysticercosis ( $T$. solium or $T$. asiatica); (ii) no geographical reference provided; (iii) based on experimental studies or solely on questionnaire surveys; and (iv) data reported were from prior 2000. No language restrictions were imposed. Only the baseline data from studies testing intervention approaches were extracted. Due to the cross-reaction with Taenia hydatigena when using serology, data based on serological testing were omitted if data from tongue or carcass inspection from the same country were available. Country reports of porcine cysticercosis (T. solium) presence (i.e. "disease present" or "limited distribution") in the period 2005-2017 were also extracted from the OIE database WAHID Interface [7].

During the second phase, backward reference searches for potential references of epidemiological studies reporting data from 2000-2018 in any of the target countries were conducted on all review articles and eligible articles found during the first search. Collaborators and known researchers from the respective countries were contacted in efforts to obtain grey literature containing epidemiological data from the requested period. Figure 1 shows a flow diagram of the applied search strategies.

In the third phase, if no data on porcine cysticercosis could be obtained from a respective target country, a country-specific PubMed search was carried out. The country-specific search was performed to confirm the presence of the parasites in human hosts within the respective country during the study period by obtaining reports of human cysticercosis, $T$. solium taeniosis, or $T$. asiatica taeniosis, respectively. The country-specific search was performed using the same date restriction as previously and using the term, e.g. ("neurocysticercosis" OR "cysticercosis" OR "taeniosis" OR "taeniasis" OR "Taenia solium" OR "Taenia asiatica") AND ("Country name"). Only the newest reports of human cysticercosis, $T$. solium taeniosis and $T$. asiatica taeniosis cases were retained, and the data only used as national level confirmation of presence if the authors provided sufficient evidence to conclude the cases were autochthonous. Furthermore, taeniosis cases were only included if infection was determined to the species level. 


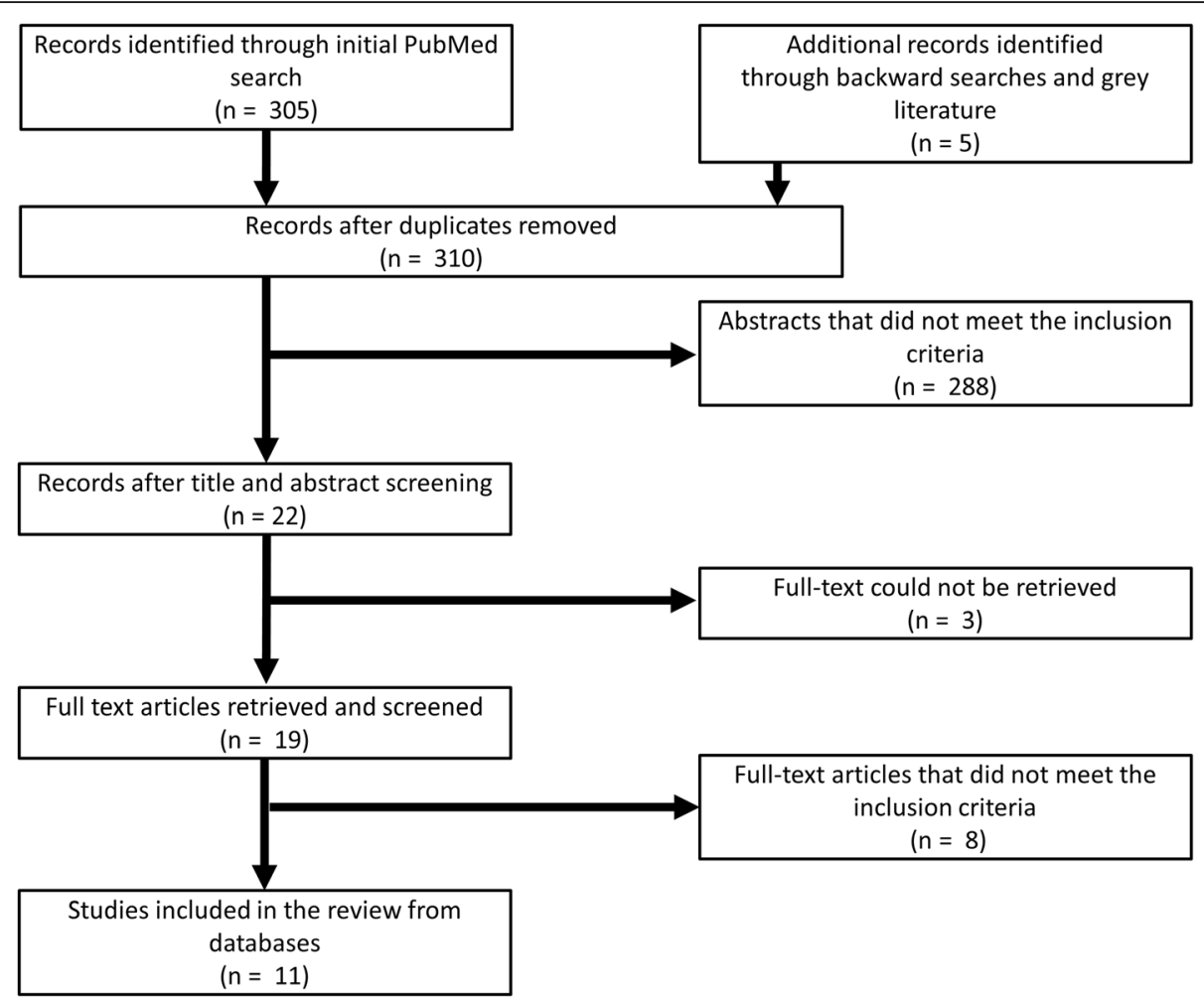

Fig. 1 Flow diagram of the search strategy for epidemiological studies on Taenia solium or Taenia asiatica in pigs

Pigs in extensive production systems

The distribution of pigs raised in extensive production systems (smallholder pig keeping) was mapped using geographical information systems based on modelled data available through http://livestock.geo-wiki.org [8, 9].

\section{Results}

The searchers revealed 310 reports, of which only 11 reports contained sufficient epidemiological data to be considered in the study. Porcine cysticercosis was confirmed to be present in eight out of the 16 countries included in this study during the period 2000 to 2018 (Table 1, Fig. 2). Taenia solium porcine cysticercosis was confirmed from all eight countries, whereas only one country (Laos) could be confirmed for the presence of $T$. asiatica porcine cysticercosis. In addition, of the eight countries with porcine cysticercosis, five were confirmed to have occurrence of $T$. solium porcine cysticercosis via the OIE database [7], and for two of those five countries (China and East Timor), OIE was the only data source confirming the occurrence of $T$. solium porcine cysticercosis that could be obtained (Table 1). No national level occurrence of porcine cysticercosis were confirmed solely based on serology. Eleven studies were identified to provide epidemiological data on porcine cysticercosis, and eight of them had sufficient data to provide information on province level distribution (Additional file 1: Table S2).

Both T. solium taeniosis and T. solium cysticercosis in humans could be confirmed in Thailand, whereas only human cysticercosis occurrence was confirmed in North Korea and the Philippines. In total, T. solium was confirmed in 11 out of the 16 countries included in this study (Fig. 3). In addition to Laos where porcine cysticercosis was confirmed, $T$. asiatica was also confirmed in six additional countries (China, Indonesia, Japan, South Korea, Thailand and Vietnam) (Fig. 4).

We identified eight studies where porcine cysticercosis occurrence could be confirmed on a province level (Table 2). One of these studies found both T. solium and T. asiatica in pigs from Huaphan Province, Laos [10]. Province level occurrence was identified in five countries (Cambodia, Indonesia, Laos, Myanmar and Vietnam) across 19 provinces. Smallholder pig keeping is believed to be widely practised throughout the region, with greater densities predicted to occur in areas of China, Myanmar, Philippines and Vietnam. Figure 5 shows the provinces found to harbour porcine cysticercosis infected pigs, overlaid with the previously modelled density of pigs kept in extensive production systems throughout the region $[8,9]$. 
Table 1 List of reports with confirmed cases of Taenia solium or Taenia asiatica in pigs and humans in the period January 1 st 2000 to June 30th 2018. Prevalence has not been included as samples are not representative, but the parasite noted as being present within a specified area based on sufficient evidence. Taeniosis and human cysticercosis data have only been included if no reports of positive pigs could be found to illustrate potential presence of the parasite within the area and only the most recent data have been included

\begin{tabular}{|c|c|c|c|c|c|}
\hline \multirow[t]{2}{*}{ Country } & \multirow{2}{*}{$\begin{array}{l}\text { T. solium } \\
\text { Porcine cysticercosis }\end{array}$} & \multirow[b]{2}{*}{ Taeniosis } & \multirow[b]{2}{*}{$\begin{array}{l}\text { Human } \\
\text { cysticercosis }\end{array}$} & \multicolumn{2}{|l|}{ T. asiatica } \\
\hline & & & & Porcine cysticercosis & Taeniosis \\
\hline Brunei & - & - & - & - & - \\
\hline Cambodia & Meat inspection of 432 pigs (29 infected) [35] & na & na & - & - \\
\hline China & OIE reported cases occurring during 2005-2017 & na & na & - & $+[18]$ \\
\hline East Timor & OIE reported cases occurring during 2005-2017 & na & na & - & - \\
\hline Indonesia & $\begin{array}{l}\text { Meat inspection of } 35 \text { pigs ( } 27 \text { infected) [36]. Post-mortem examination of } \\
\text { an infected pig [37]. Post-mortem examination of } 3 \text { pigs ( } 1 \text { infected) [38]. } \\
\text { Meat inspection of } 6 \text { seropositive pigs ( } 6 \text { infected) [39] }\end{array}$ & na & na & - & $+[21]$ \\
\hline Japan & - & - & - & - & $+[22]$ \\
\hline Laos & $\begin{array}{l}\text { Meat inspection of } 590 \text { pigs (5 infected) [10]. OlE reported cases } \\
\text { occurring during } 2005-2017\end{array}$ & na & na & $\begin{array}{l}\text { Meat inspection of } 590 \\
\text { pigs (1 infected) [10] }\end{array}$ & na \\
\hline Malaysia & - & - & - & - & - \\
\hline Mongolia & OIE reported cases occurring during 2005-2017 & na & na & - & - \\
\hline Myanmar & Meat inspection of 300 pigs (71 infected) [40] & na & na & - & - \\
\hline $\begin{array}{l}\text { North } \\
\text { Korea }\end{array}$ & - & - & $+[27]$ & - & - \\
\hline Philippines & - & - & $+[28]$ & - & - \\
\hline Singapore & - & - & - & - & - \\
\hline $\begin{array}{l}\text { South } \\
\text { Korea }\end{array}$ & - & - & - & - & $+[32]$ \\
\hline Thailand & - & $+[33]$ & $+[33]$ & - & $+[33]$ \\
\hline Vietnam & $\begin{array}{l}\text { Tongue examination of } 172,087 \text { pigs (109 infected) [41]. OlE reported } \\
\text { cases occurring during 2005-2017 }\end{array}$ & na & na & - & $+[12]$ \\
\hline
\end{tabular}

Abbreviation: na not available

\section{Discussion}

On a national level, of the 16 countries covering East and Southeast Asia, eight were found to have confirmed reports of $T$. solium porcine cysticercosis and only Laos had confirmed reports of pigs being infected with $T$. asiatica during the study period. Discrepancy in reports of $T$. solium porcine cysticercosis and reports of infections in humans occurred as only human infections were observed for three countries (North Korea, Philippines and Thailand). This is most likely a consequence of epidemiological surveys in pigs not having been performed. The results of this study also underlined the discrepancy between the known distribution of pigs infected with $T$. asiatica, which were only reported from one province in Laos, and human $T$. asiatica taeniosis cases, which were reported from an additional six countries. This indicates that $T$. asiatica porcine cysticercosis is vastly underreported, and that more epidemiological survey data from across the region are required in order to determine the burden of this parasite within East and Southeast Asia.
Although porcine cysticercosis and taeniosis were reported throughout the region, little data were available to confirm the distribution of porcine cysticercosis on a provincial level (first-administration subdivision level). Provinces with infected pigs were identified in northern Laos and Vietnam, central Myanmar, southern Laos and Sumatra, Bali and Papua. Using modelled distribution data of the density of pigs in extensive production systems can provide a cost-effective approach to map out areas potentially at risk of porcine cysticercosis. The majority of pigs kept in extensive systems were predicted to be found in China. According to the global burden of disease study in 2013, China has the second most reported cases of human cysticercosis globally [11], but epidemiological studies or data on porcine cysticercosis originating from China are unavailable to the international research community. Higher densities of pigs in extensive systems were also predicted in Myanmar, southern and northern Vietnam, the Philippines and China. Modelling the distribution of pigs is limited by the quality of the underlying data. Studies are still missing to determine to which 


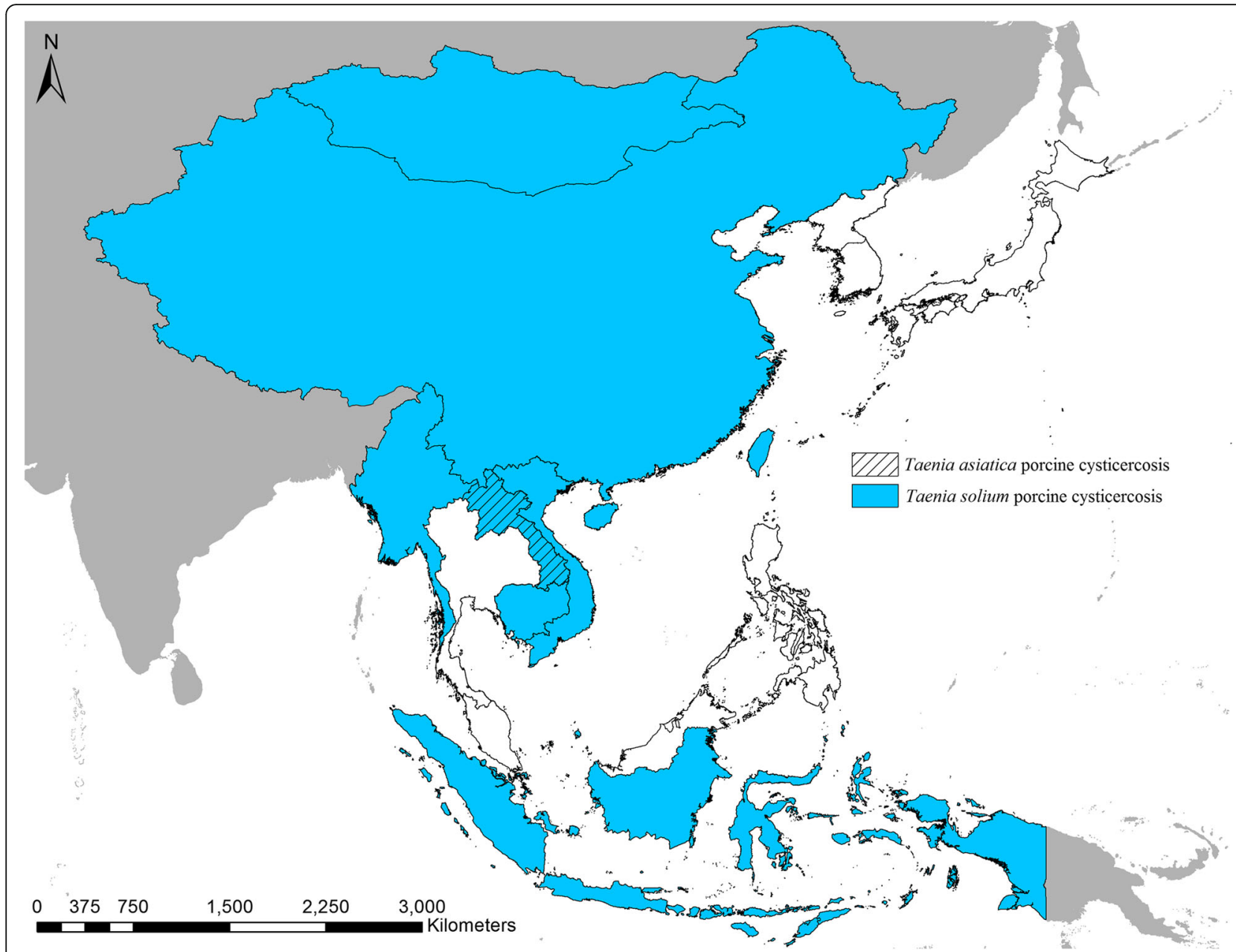

Fig. 2 Countries in East and Southeast Asia with confirmed reports of porcine cysticercosis (Taenia solium/Taenia asiatica) based on post-mortem data from the period January 1st 2000 to June 30th 2018

degree risk of porcine cysticercosis can be correlated with the density of pigs in extensive production systems. However, the modelled distribution provides an initial approach to identify areas where epidemiological data will most likely be required to accurately model the regional distribution of porcine cysticercosis.

With increased international travel and movement of people across borders, case reports of taeniosis are not necessarily reliable to confirm active transmission of the parasite from a specific location, which requires more costly epidemiological surveys. However, a newly developed assay based on multiplex qPCR on stool samples appears to be able to distinguish between the three species of Taenia tapeworms (T. asiatica, T. saginata and T. solium) causing taeniosis in humans [12]. Available data on taeniosis where no species identification has been made is not useful in the determination of burden of the various parasites. Relying on porcine cysticercosis surveillance to establish parasite presence is justifiable and an excellent indicator of active transmission due to pigs' relative short lifespan and limited distance in geographical movement. However, surveillance of porcine cysticercosis also has diagnostic complications. No national level occurrences of porcine cysticercosis were confirmed solely based on serology in this study. Serological confirmation of porcine cysticercosis, if there is a presence of $T$. hydatigena, becomes highly problematic due to cross-reactions in the assays. The reported prevalence of $T$. hydatigena in Asia has been relatively high [13] compared to reports from Africa [14], which underlines the importance of confirming porcine cysticercosis based on lingual or post-mortem examinations of pigs.

\section{Brunei Darussalam}

We were not able to identify any data to suggest that porcine cysticercosis is a problem in Brunei Darussalam. Nor was any other literature found that could indicate the presence of either $T$. solium or T. asiatica taeniosis in the human population. The population in Brunei is predominantly Muslim and therefore do not consume 


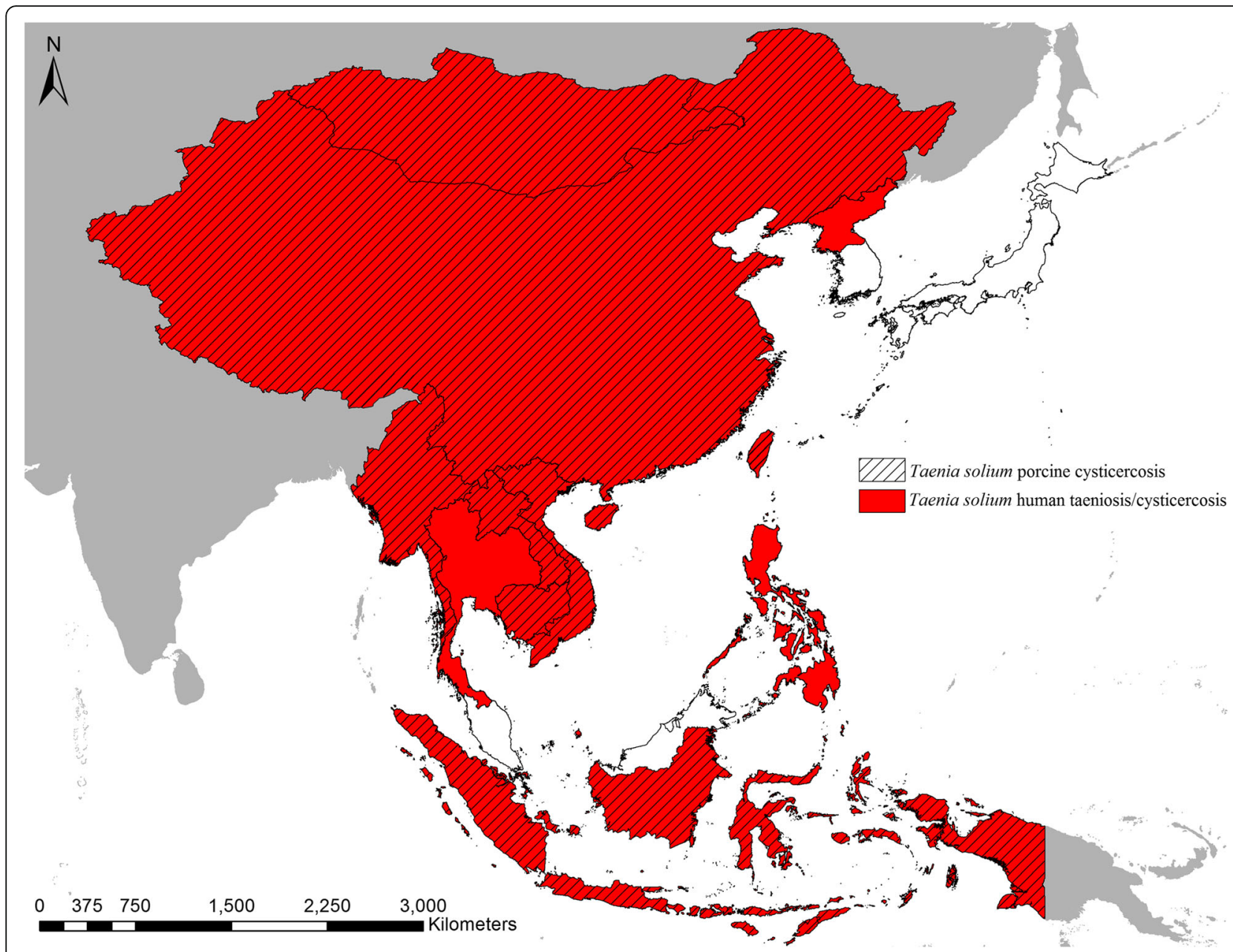

Fig. 3 Countries in East and Southeast Asia with confirmed reports of Taenia solium in humans and specifically reports of $T$. solium porcine cysticercosis in the period January 1st 2000 to June 30th 2018

pork, potentially the primary cause of the pathogens absence. The need for further investigations in Brunei currently seems unwarranted.

\section{Cambodia}

As illustrated in Fig. 5, porcine cysticercosis due to $T$. solium is widely endemic in Cambodia. However, the data available were based on limited sample sizes from the affected provinces and more epidemiological surveys are therefore necessary to establish the degree of endemicity with the country. Cambodian schoolchildren have been found infected with Taenia spp. [15], but reports of human taeniosis due to T. solium or T. asiatica are not well documented from Cambodia. It is not clear to what degree neurocysticercosis is a problem within Cambodia as no information is available, but in a recent study, people were found seropositive for cysticercosis [16]. More detailed mapping of both Taenia species is recommended in Cambodia in order to estimate burden and implement control initiatives accordingly.

\section{China}

There are older reports of porcine cysticercosis being a problem throughout China [17], but no current reports of porcine cysticercosis are readily available. Even though no reports of porcine cysticercosis due to $T$. asiatica could be found, there have been recent reports of $T$. asiatica taeniosis in China, suggesting that this parasite might be common in certain areas [18]. More epidemiological data are required to map to extent of the problem in China. A recent epidemiological study of human cysticercosis in the central part of China indicates that $T$. solium is still a major problem within China [19], warranting further surveys to determine the distribution and burden of T. solium as well. Chinese Taiwan has previously been endemic for both $T$. solium and $T$. asiatica, but no current information is readily available to describe the status of these two parasites. Epidemiological surveys are highly warranted to estimate the distribution and prevalence on Chinese Taiwan, due to the history of occurrence [5]. 


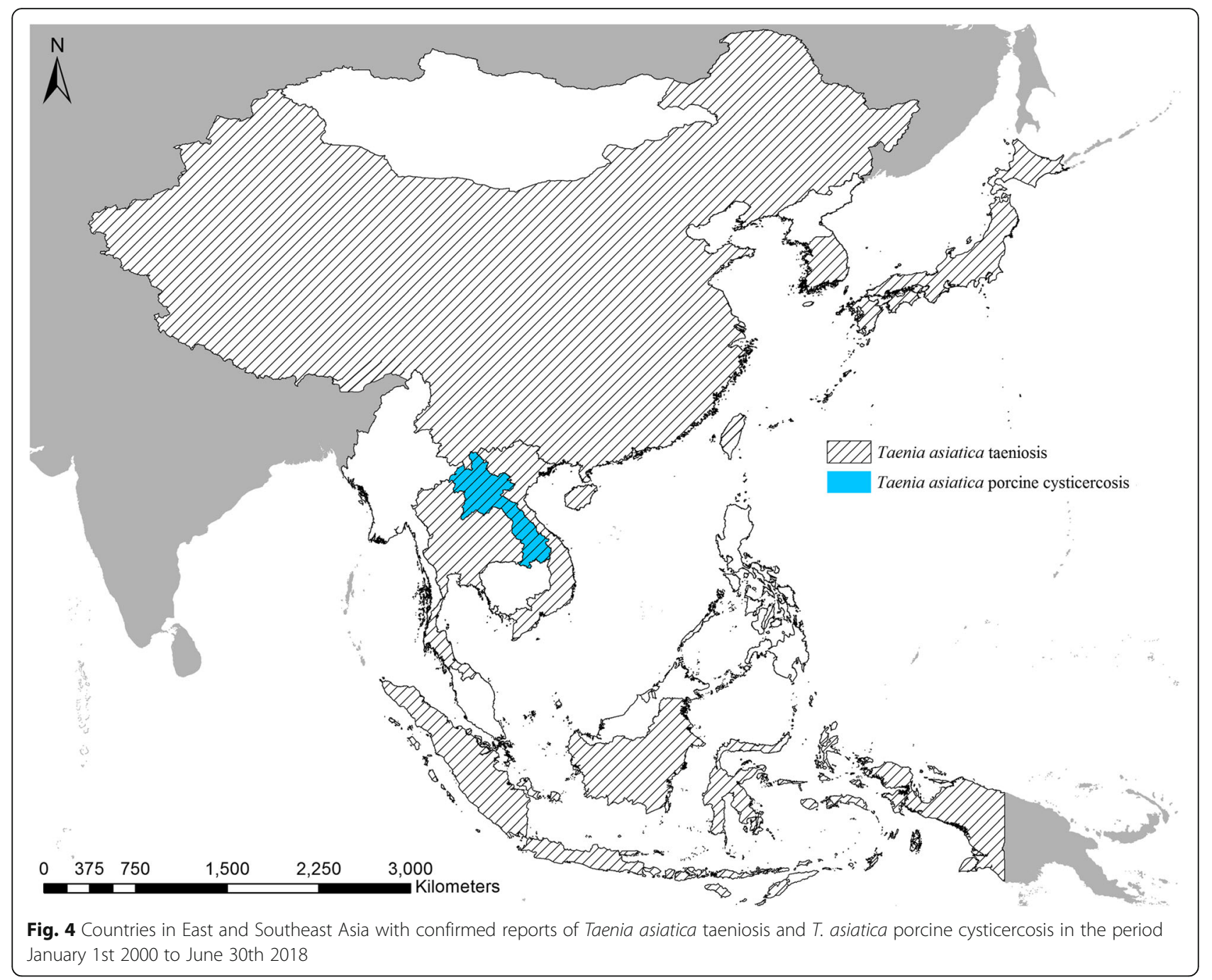

\section{East Timor}

OIE reported that $T$. solium porcine cysticercosis occurs in the country, but we were unable to find other reports. No reports of $T$. asiatica in either pigs or humans could be found. The OIE reports need to be followed-up by epidemiological investigations to determine the distribution of T. solium porcine cysticercosis in East Timor.

\section{Indonesia}

The reports of porcine cysticercosis from Indonesia are few, but it is also likely that transmission of T. solium to pigs is highly clustered and restricted to areas where Islam is not practiced predominantly. This study provides a rough overview of areas that should be considered for epidemiological surveys to establish the extent

Table 2 The first-level administrative subdivision (province) occurrence of Taenia solium porcine cysticercosis in East and Southeast Asia from January 1st 2000 to June 30th 2018 based on post-mortem examinations

\begin{tabular}{lll}
\hline Country & Reference & First-level administrative subdivision (Province) \\
\hline Cambodia & {$[35]$} & Banteay Mean Chey, Battambang, Kampong Cham, Kampong Chhnang, Kampong Speu, Kampong Thom, Kandal, Koh Kong \\
Indonesia & {$[36-39]$} & Papua, Bali, Lampung \\
Laos & {$[10]$} & Luangprabang, Huaphan ${ }^{a}$ \\
Myanmar & {$[40]$} & Naypyidaw \\
Vietnam & {$[41]$} & Yen Bai, Lao Cai, Nghe An, Bac Kan, Bac Giang
\end{tabular}




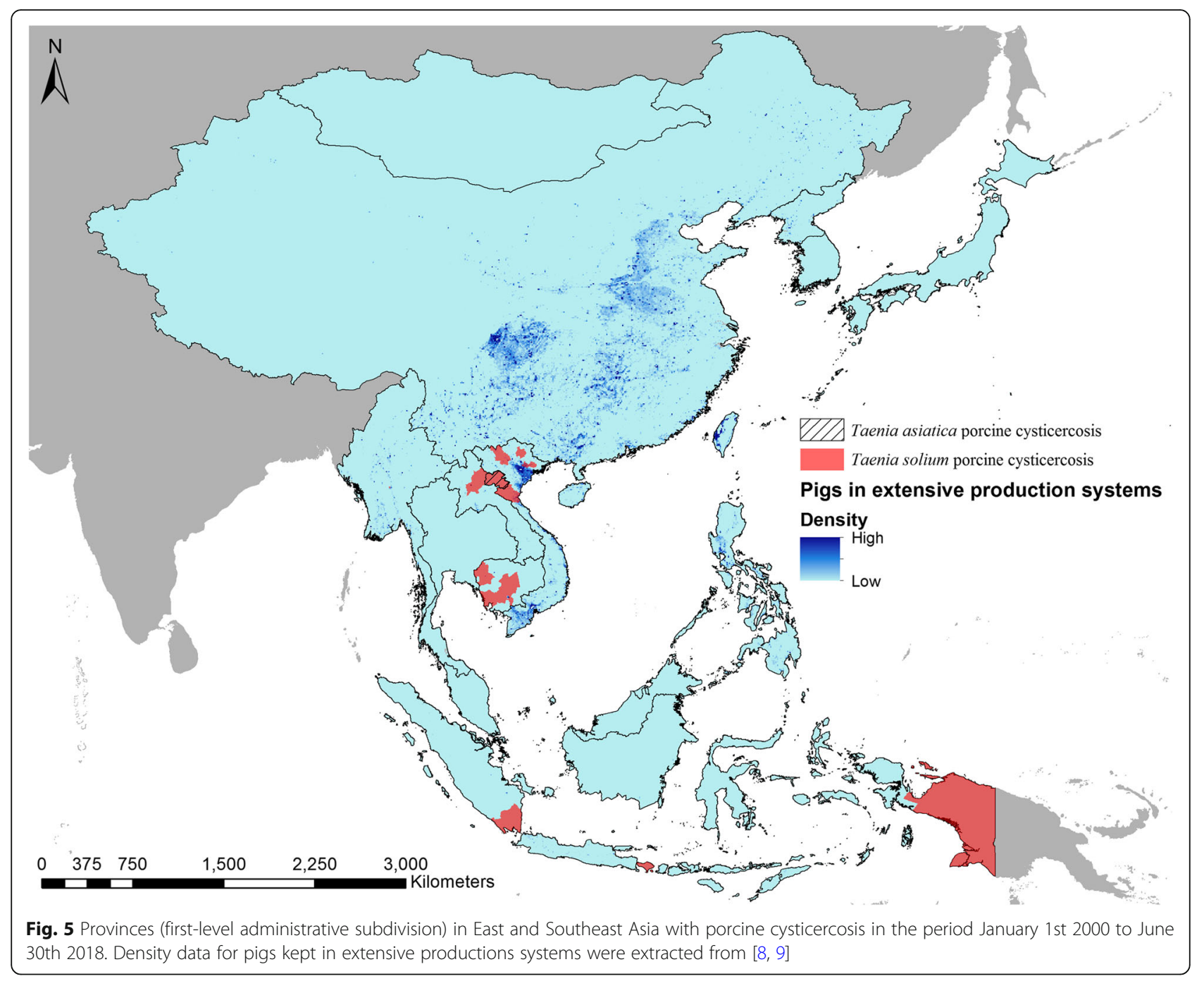

of T. solium distribution throughout Indonesia. Taenia asiatica has not been reported in pigs from any recent studies, but there have been reports of $T$. asiatica found in the livers of pigs in the past [20]. More recent reports of $T$. asiatica taeniosis exist, but not directly published yet [21].

\section{Japan}

There are no recent reports of porcine cysticercosis in Japan, and the country is not considered to have active transmission of porcine cysticercosis. However, recently human T. asiatica taeniosis cases have been confirmed within Japan [22]. In addition, imported cases of taeniosis can still occur and cause sporadic outbreaks of cysticercosis. Recently, an imported case of $T$. asiatica taeniosis believed to have originated in the Philippines was reported in Japan [23].

\section{Laos}

Recently all three species, $T$. solium, $T$. saginata and $T$. asiatica, were found in people living in Laos [24]. The study also reported a number of people being seropositive for cysticercosis. Together, these are clear indications that active transmission of both $T$. solium and $T$. asiatica presently occurs in Laos. However, more epidemiological data are needed to establish in which parts of the country transmission of porcine cysticercosis occurs frequently.

\section{Malaysia}

There are no current reports of porcine cysticercosis in Malaysia where the predominant religion is Islam. Older studies have indicated that rural areas populated with communities not belonging to Islam, have been exposed to T. solium. In 1996, 135 blood samples collected were 
analysed using an Ab-ELISA and a prevalence of $2.2 \%$ was found [25].

\section{Mongolia}

OIE reported cases of $T$. solium porcine cysticercosis occurring within Mongolia. However, no reports of $T$. solium infections in humans were found nor were any reports of T. asiatica. Epidemiological surveys should be performed in the areas reported to the OIE to estimate the extent of the T. solium porcine cysticercosis distribution in Mongolia.

\section{Myanmar}

Taenia solium porcine cysticercosis was confirmed from Myanmar and the presences of $T$. asiatica have been suggested to occur, but so far, there are no published reports of infected pigs based on post-mortem examination from Myanmar. Recently both people and pigs have been found seropositive for cysticercosis as well as people positive for taeniosis [26].

\section{North Korea}

Very limited information about the presence of disease exists from North Korea, but one study based on serology in humans suggest that $T$. solium is actively transmitted in North Korea [27]. There are no reports of $T$. asiatica from North Korea. Whether porcine cysticercosis is endemic in North Korea remains unknown, and epidemiological surveys do not seem to be implementable in the near future.

\section{Philippines}

Although there were no recent reports of porcine cysticercosis from the Philippines, a recent community survey found a seroprevalence among humans of almost $25 \%$ based on antibodies [28], which is a strong indicator of $T$. solium occurrence. A presumed imported case of $T$. asiatica taeniosis in Japan, based on the patient's travel history, was believed to have originated in the Philippines [23]. This could indicate that $T$. asiatica is still endemic in certain parts of the Philippines, but no current information is available.

\section{Singapore}

Singapore is not considered endemic for porcine cysticercosis, but does receive reports occasionally of human cysticercosis, presumably due to the influx of foreign travellers and workers [29]. However, a substantial amount of pork is consumed annually in Singapore, but pork production is minimal. Singapore imports frozen or processed pork from numerous countries, but until recently the only source of fresh pork was from Riau Islands Province, Indonesia. Import of live pigs from Malaysia has recently commenced after being banned in
1999 due to a Nipah Virus outbreak [30]. This could increase the risk of importing cases of porcine cysticercosis into the country, but the risk of active transmission in Singapore is minimal.

\section{South Korea}

Cysticercosis is not considered endemic in South Korea [31]. However, a recent case report of T. asiatica taeniosis showed that sporadic transmission is still suspected within South Korea [32]. Epidemiological surveys of pigs in rural areas are needed to confirm or refute the presence of porcine cysticercosis in South Korea.

\section{Thailand}

Even though no data exist for pigs, a community-based survey conducted in two villages in central Thailand during 2007 and 2008, reported both the presence of $T$. solium (taeniosis and cysticercosis) and T. asiatica in the human population [33]. Endemic foci may exist throughout the country, and the study by Anantaphruti et al. [33] warrants further investigations in the porcine populations.

\section{Vietnam}

OIE and epidemiological surveys confirm the presence of T. solium in Vietnam. Data describing the distribution are still very limited. Although no recent reports of $T$. asiatica porcine cysticercosis could be found from Vietnam, there have been several reports of taeniosis cases, recently reviewed by Ng-Nguyen et al. [34]. Studies are needed to map the distribution and determine the burden of T. solium and T. asiatica within Vietnam.

\section{Conclusions}

A common feature for all countries is that the detailed national distributions of porcine cysticercosis are missing. The discrepancies between countries reporting taeniosis and the occurrence of porcine cysticercosis agents, both $T$. solium and $T$. asiatica, suggest that both parasites are underreported. More should be done to uncover the distribution of porcine cysticercosis caused by T. solium and T. asiatica in East and Southeast Asia. This will provide researchers and stakeholders with the opportunity to estimate the burden imposed by these two parasites on societies within the region. We have here attempted to provide a rough estimate of the areas at risk of porcine cysticercosis based on the density of pigs kept by smallholder farmers. Future epidemiological surveys will be able to answer to what degree this approach can be used to determine which areas to include in control initiatives against not only $T$. solium, but also against $T$. asiatica. Due to the paucity of epidemiological data, the approach taken here to risk mapping is an initial start. 


\section{Additional file}

Additional file 1: Table S1. Full search output from the initial literature search. Table S2. List of studies that were identified to provide epidemiological data on porcine cysticercosis. (XLSX 45 kb)

\begin{abstract}
Acknowledgments
Members of the RNAS+ countries (http://www.rnas.org.cn/) for their time spend searching for grey literature. Ministry of Research, Technology, and Higher Education Republic of Indonesia for granting PMDSU Research Grant for Dr Fadjar Satrija.
\end{abstract}

\section{Funding}

Not applicable.

\section{Availability of data and materials}

Data supporting the conclusions of this article are included within the article and its additional file. All references found eligible in our literature review are included in Additional file 1.

\section{Authors' contributions}

All authors participated in the design of the study. UCB carried out the literature review and coordinated the data collection. UCB created the figures and drafted the manuscript, with subsequent input from $\mathrm{NMH}$, FS, VK, XZ and ALW. All authors read and approved the final manuscript.

\section{Ethics approval and consent to participate}

Not applicable.

\section{Consent for publication}

Not applicable.

\section{Competing interests}

The authors declare that they have no competing interests.

\section{Publisher's Note}

Springer Nature remains neutral with regard to jurisdictional claims in published maps and institutional affiliations.

\section{Author details}

${ }^{1}$ One Health Center for Zoonoses and Tropical Veterinary Medicine, Ross University School of Veterinary Medicine, Basseterre, Saint Kitts and Nevis. ${ }^{2}$ Department of Parasitology, Institute of Ecology and Biological Resources, Vietnam Academy of Science and Technology, Hanoi, Vietnam. ${ }^{3}$ Department of Animal Infectious Diseases, Faculty of Veterinary Medicine, Bogor Agricultural University, Bogor, Indonesia. ${ }^{4}$ National Center for Parasitology, Entomology and Malaria Control, Ministry of Health, Phnom Penh, Cambodia. ${ }^{5}$ National Institute of Parasitic Diseases, China CDC, Shanghai, China.

\section{Received: 10 August 2018 Accepted: 19 November 2018}

Published online: 29 November 2018

\section{References}

1. Torgerson PR, Devleesschauwer B, Praet N, Speybroeck N, Willingham AL, Kasuga F, et al. World Health Organization estimates of the global and regional disease burden of 11 foodborne parasitic diseases, 2010: a data synthesis. PLoS Med. 2015;12:e1001920.

2. Havelaar AH, Kirk MD, Torgerson PR, Gibb HJ, Hald T, Lake RJ, et al. World Health Organization global estimates and regional comparisons of the burden of foodborne disease in 2010. PLOS Med. 2015:12:e1001923.

3. Braae UC, Devleesschauwer B, Sithole F, Wang Z, Willingham AL. Mapping occurrence of Taenia solium taeniosis/cysticercosis and areas at risk of porcine cysticercosis in Central America and the Caribbean basin. Parasit Vectors. 2017:10:424

4. Braae UC, Saarnak CF, Mukaratirwa S, Devleesschauwer B, Magnussen P, Johansen MV. Taenia solium taeniosis/cysticercosis and the co-distribution with schistosomiasis in Africa. Parasit Vectors. 2015;8:323.
5. Wu HW, Ito A, Ai L, Zhou XN, Acosta LP, Lee Willingham A III. Cysticercosis/ taeniasis endemicity in Southeast Asia: current status and control measures. Acta Trop. 2017;165:121-32.

6. Sikasunge CS, Phiri IK, Phiri AM, Dorny P, Siziya S, Willingham AL 3rd. Risk factors associated with porcine cysticercosis in selected districts of Eastern and Southern provinces of Zambia. Vet Parasitol. 2007;143:59-66.

7. OIE: World Animal Health Information Database (WAHID) Interface. 2018 http://www.oie.int/wahis_2/public/wahid.php/Wahidhome/Home. 8 Aug 2018.

8. Gilbert M, Conchedda G, Van Boeckel TP, Cinardi G, Linard C, Nicolas G, et al. Income disparities and the global distribution of intensively farmed chicken and pigs. PLoS One. 2015;10:e0133381.

9. Robinson TP, Wint GR, Conchedda G, Van Boeckel TP, Ercoli V, Palamara E, et al. Mapping the global distribution of livestock. PLoS One. 2014;9:e96084

10. Conlan JV, Vongxay K, Khamlome B, Dorny P, Sripa B, Elliot A, et al. A cross-sectional study of Taenia solium in a multiple taeniid-endemic region reveals competition may be protective. Am J Trop Med Hyg. 2012;87:281-91.

11. Herricks JR, Hotez PJ, Wanga V, Coffeng LE, Haagsma JA, Basanez MG, et al. The global burden of disease study 2013: what does it mean for the NTDs? PloS Negl Trop Dis. 2017;11:e0005424.

12. Ng-Nguyen D, Stevenson MA, Dorny P, Gabriel S, Vo TV, Nguyen VT, et al. Comparison of a new multiplex real-time PCR with the Kato-Katz thick smear and copro-antigen ELISA for the detection and differentiation of Taenia spp. in human stools. PloS Negl Trop Dis. 2017;11:e0005743.

13. Nguyen MT, Gabriel S, Abatih EN, Dorny P. A systematic review on the global occurrence of Taenia hydatigena in pigs and cattle. Vet Parasitol. 2016;226:97-103.

14. Braae UC, Kabululu M, Normark ME, Nejsum P, Ngowi HA, Johansen MV Taenia hydatigena cysticercosis in slaughtered pigs, goats, and sheep in Tanzania. Trop Anim Health Prod. 2015:47:1523-30.

15. Kuong K, Fiorentino M, Perignon M, Chamnan C, Berger J, Sinuon M, et al Cognitive performance and iron status are negatively associated with hookworm infection in Cambodian schoolchildren. Am J Trop Med Hyg. 2016;95:856-63.

16. Priest JW, Jenks MH, Moss DM, Mao B, Buth S, Wannemuehler $\mathrm{K}$, et al. Integration of multiplex bead assays for parasitic diseases into a national, population-based serosurvey of women 15-39 years of age in Cambodia. PloS Negl Trop Dis. 2016:10:e0004699.

17. Li T, Ito A, Craig PS, Chen X, Qiu D, Zhou X, et al. Taeniasis/cysticercosis in China. Southeast Asian J Trop Med Public Health. 2007:38(Suppl. 1):131-9.

18. Wang L, Luo X, Hou J, Guo A, Zhang S, Li H, et al. Infection of Taenia asiatica in a Bai Person in Dali, China. Korean J Parasitol. 2016:54:67-70.

19. Openshaw JJ, Medina A, Felt SA, Li T, Huan Z, Rozelle S, et al. Prevalence and risk factors for Taenia solium cysticercosis in school-aged children: a school based study in western Sichuan, People's Republic of China. Plos Negl Trop Dis. 2018;12:e0006465

20. Wandra T, Ito A, Swastika K, Dharmawan NS, Sako Y, Okamoto M. Taeniases and cysticercosis in Indonesia: past and present situations. Parasitology. 2013:140:1608-16.

21. Wandra T, Depary AA, Sutisna P, Margono SS, Suroso T, Okamoto M, et al. Taeniasis and cysticercosis in Bali and North Sumatra, Indonesia. Parasitol Int. 2006;55(Suppl.):S155-60.

22. Yamasaki H, Morishima Y, Sugiyama H. Confirmation of Taenia asiatica infection in Japan in August 2016 - Chiba Prefecture. Infect Agents Surveillance Rep. 2016:37:206

23. Namikawa H, Takemoto Y, Shimazaki I, Makuuchi A, Kobayashi M, Kinuhata S, et al. A case of imported Taenia asiatica infection in Japan. Jpn J Infect Dis. 2018;71:170-1

24. Sato MO, Sato M, Yanagida T, Waikagul J, Pongvongsa T, Sako Y, et al. Taenia solium, Taenia saginata, Taenia asiatica, their hybrids and other helminthic infections occurring in a neglected tropical diseases' highly endemic area in Lao PDR. PloS Negl Trop Dis. 2018:12:e0006260.

25. Noor Azian MY, Hakim SL, Sumiati A, Norhafizah M. Seroprevalence of cysticercosis in a rural village of Ranau, Sabah, Malaysia. Southeast Asian J Trop Med Public Health. 2006;37:58-61.

26. McCleery EJ, Patchanee $P$, Pongsopawijit $P$, Chailangkarn $S$, Tiwananthagorn $S$, Jongchansittoe $P$, et al. Taeniasis among refugees living on ThailandMyanmar border, 2012. Emerg Infect Dis. 2015;21:1824-6.

27. Shen C, Li S, Zheng S, Choi MH, Bae YM, Hong ST. Tissue parasitic helminthiases are prevalent at Cheongjin, North Korea. Korean J Parasitol. 2007:45:139-44. 
28. Xu JM, Acosta LP, Hou M, Manalo DL, Jiz M, Jarilla B, et al. Seroprevalence of cysticercosis in children and young adults living in a helminth endemic community in Leyte, the Philippines. J Trop Med. 2010;2010:603174.

29. Foo SS, Selvan VS, Clarke MJ, Shen EJ. Unusual cause of seizures in Singapore: neurocysticercosis. Singapore Med J. 2008;49:e147-50.

30. Chua KB, Goh KJ, Wong KT, Kamarulzaman A, Tan PSK, Ksiazek TG, et al. Fatal encephalitis due to Nipah virus among pig-farmers in Malaysia. Lancet. 1999;354:1257-9.

31. Chai JY. Human taeniasis in the Republic of Korea: hidden or gone? Korean J Parasitol. 2013;51:9-17.

32. Kim HU, Chung YB. A case of Taenia asiatica infection diagnosed by colonoscopy. Korean J Parasitol. 2017;55:65-9.

33. Anantaphruti MT, Okamoto M, Yoonuan T, Saguankiat S, Kusolsuk T, Sato M, et al. Molecular and serological survey on taeniasis and cysticercosis in Kanchanaburi Province, Thailand. Parasitol Int. 2010;59:326-30.

34. Ng-Nguyen D, Stevenson MA, Traub RJ. A systematic review of taeniasis, cysticercosis and trichinellosis in Vietnam. Parasit Vectors. 2017:10:150

35. Sovyra T. Prevalence of porcine cysticercosis, trichinellosis in slaughter pigs of Cambodia. MSc Thesis. Chiang Mai University, Thailand and Freie Universitat, Germany; 2005.

36. Maitindom FD. Study of the incidence of cysticercosis in pigs sold at Jibama market in Jayawijaya Regency, Papua. MSc Thesis. Bogor Agricultural University, Bogor; 2008.

37. Dharmawan NS, Swastika K, Putra IM, Wandra T, Sutisna P, Okamoto M, et al. Present situation and problems of cysticercosis in animal in Bali and Papua. J Veteriner. 2013;2:154-62.

38. Yulianto HH, Satrija F, Lukman DW, Sudarwanto M. Seroprevalence and risk factors of porcine cysticercosis in Way Kanan District, Lampung Province. Indonesia. Glob Vet. 2014;12:774-81.

39. Swastika K, Dharmawan NS, Suardita IK, Kepeng IN, Wandra T, Sako Y, et al. Swine cysticercosis in the Karangasem district of Bali, Indonesia: an evaluation of serological screening methods. Acta Trop. 2016;163:46-53.

40. Khaing TA, Bawm S, Wai SS, Htut Y, Htun LL. Epidemiological survey on porcine cysticercosis in Nay Pyi Taw area, Myanmar. J Vet Med. 2015; 2015:340828.

41. Doanh N. Results of research on cysticercosis in pig in some northern provinces of Vietnam. J Biol. 2005;27:55-8.

Ready to submit your research? Choose BMC and benefit from:

- fast, convenient online submission

- thorough peer review by experienced researchers in your field

- rapid publication on acceptance

- support for research data, including large and complex data types

- gold Open Access which fosters wider collaboration and increased citations

- maximum visibility for your research: over $100 \mathrm{M}$ website views per year

At $\mathrm{BMC}$, research is always in progress.

Learn more biomedcentral.com/submissions 